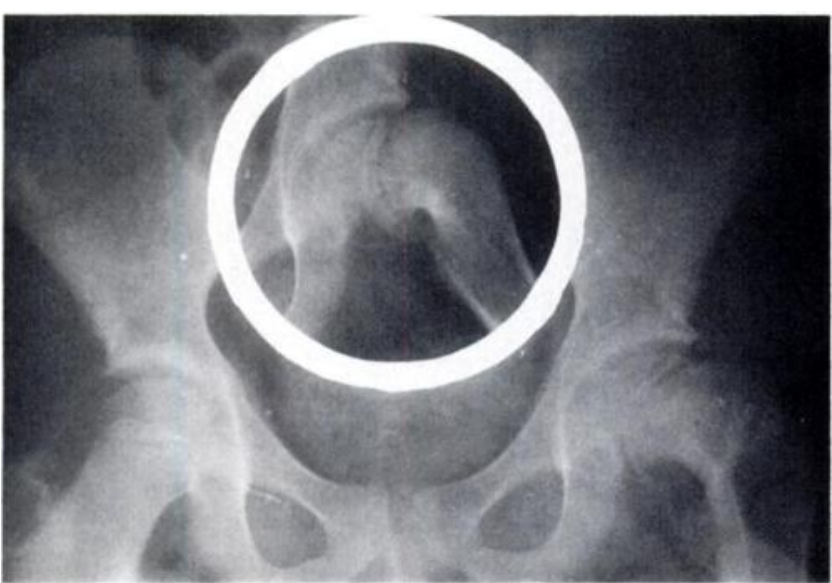

Fig. 1

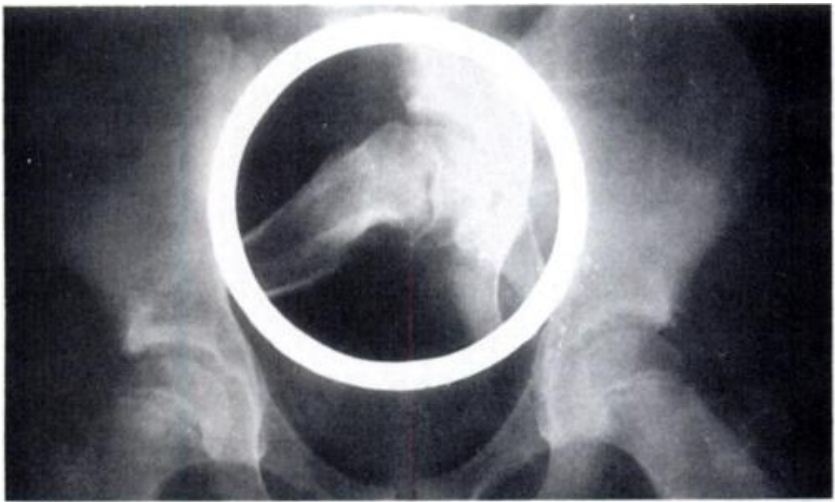

Fig. 2

One month later, her identical twin presented with a painful right hip of three weeks' duration. The limb was held laterally rotated; abduction and medial rotation were limited. Radiographs showed a slipped capital epiphysis of the right femur (Fig. 2) and pin fixation was performed.

Both girls were otherwise healthy with no history of trauma. Their HLA phenotype determined by the microlymphocytotoxic technique is A 11, B 12 (44).

Discussion. The reported familial incidence of slipped capital femoral epiphysis suggests a genetic predisposition which may be inherited as an autosomal dominant trait with variable penetrance (Rennie 1967, 1982). A family history should therefore be sought in all cases.

This is the second report of slipped epiphyses in identical twins. It seems that if one twin presents with an epiphyseal slip, the other should be examined. Further studies of familial cases of slipped epiphysis may help to elucidate the genetic predisposition; more HLA phenotype determinations may lead to the isolation of a genetic marker.

I would like to thank Mr R. J. Pusey, FRCS. Consultant Orthopaedic Surgeon. Orsett Hospital, Near Grays. Essex, for permission to report his patients.

\section{REFERENCES}

Gorin RL. Slipped capital femoral epiphyses in identical twins: report of a case. J Am Osteopath Assoc 1977:77:1248.

Rennie AM. Familial slipped upper femoral epiphysis. J Bone Joint Surg [Br] 1967;49-B:535-9.

Rennie AM. The inheritance of slipped upper femoral epiphysis. $J$ Bone Joint Surg [Br] 1982;64-B: 180 4 .

H. A. R. Gajraj, BSc, FRCS, Surgical Registrar

St Thomas' Hospital, Lambeth Palace Road. London SEI 7EH, England.

C 1986 British Editorial Society of Bone and Joint Surgery $0301-620 \mathrm{X} / 86 / 4 \mathrm{R} 04 \$ 2.00$

\title{
GROSS DISPLACEMENT OF A FEMORAL SHAFT FRACTURE
}

\section{A. SIMPSON}

Case report. A motorcyclist involved in a road traffic accident was admitted from the accident department with an open wound of his right thigh. Radiographs (Figs 1 and 2) showed a large loose fragment of femoral shaft and several smaller fragments, but no actual fracture was visible. More radiographs were taken but still no fracture was seen. Light dawned when it was appreciated that a second motorcyclist admitted at the same time, also with an open wound of the thigh, had lost a large piece of his femur (Fig. 3). The explanation for this curious finding was provided when a detailed history was obtained.

D. A. Simpson. FRCS. Orthopaedic Registrar Westminster Hospital. Dean Ryle Street, London SWIP 2AP. England.

c 1986 British Editorial Society of Bone and Joint Surgery $0301620 \times 86 / 4 R 03 \$ 2.00$
The first motorcyclist (A) had pulled out to pass a coach which suddenly swerved to the right to negotiate a sharp left-hand turn; he collided with the second motorcyclist (B) who had been travelling in the opposite direction. The two met thigh-to-thigh, shattering B's femur. A portion of this had acted like a spear, entering A's thigh.

All that A needed in the way of treatment was debridement, including removal of some dead muscle and the intruding piece of bone; the wound was left open and healed satisfactorily. B, in addition to his fractured femur, had a fractured pelvis and also an open fracturedislocation of the tarsus for which a Syme's amputation was necessary. The femur was treated with external fixation; six weeks later the defect was filled by a free iliac crest graft using microvascular techniques; satisfactory union was achieved.

Discussion.The percutaneous introduction of foreign ob- 


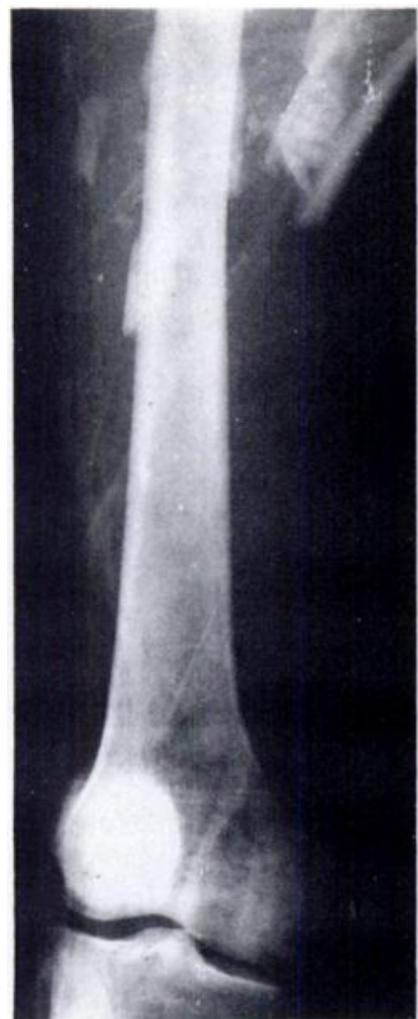

Fig. 1

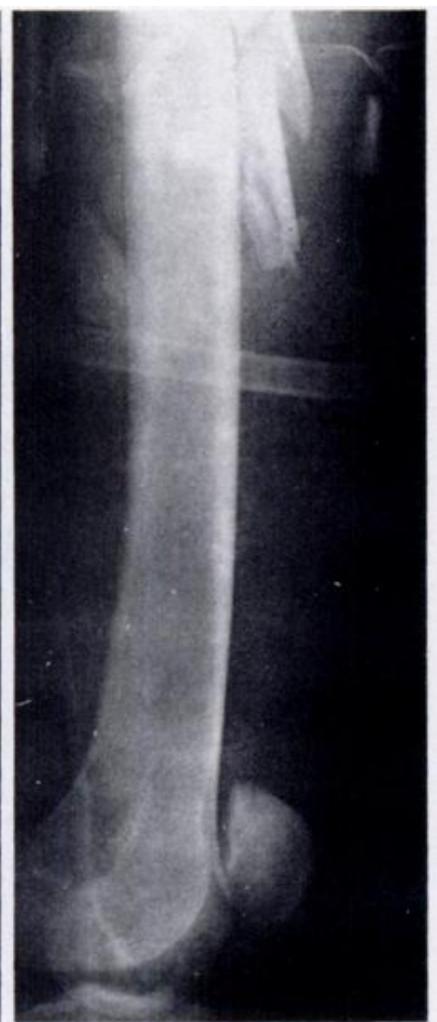

Fig. 2

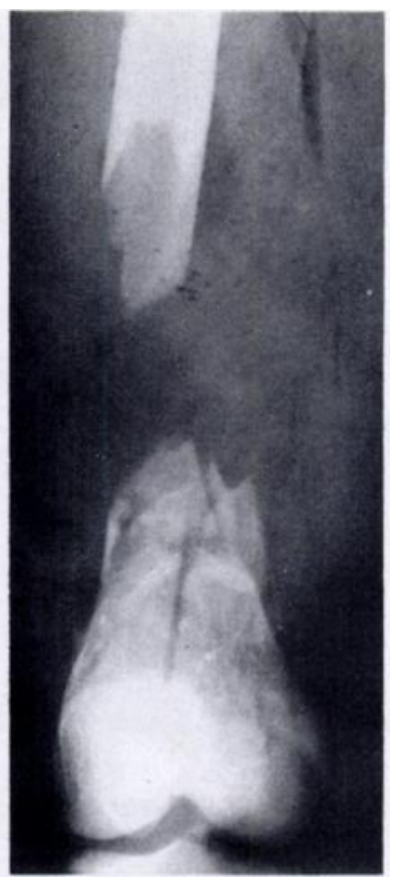

Fig. 3

Cyclist B jects into the human body is well known to surgeons. In times of war and after terrorist activities, it is not uncommon to find bullets, nails, shrapnel, wood and clothing carried into wounds. However, the introduction of a part of one human being into another by accident is extremely rare.

Ziperman and McGinty (1964) and Lynch (1980) reported cases in which a pedestrian struck by a car and sustaining a compound injury to the lower limb had been thrown against another pedestrian: the exposed bone acted as a "weapon", stabbing the second person and leaving behind fragments of bone.

Even more remarkable is the case described by Kirkup (1965) of a motorcyclist who, admitted after an accident, had nine inches of his femoral shaft missing. A search was unavailing until some 24 hours after the accident when "a police dog quickly discovered the bone in a hedge". Once the thigh had healed the piece of bone was autoclaved and reinserted, apparently with success. Whether in our case we might have employed this technique is an open question. What is undeniable is that, in any high-speed collision between two individuals, the possibility that bone has been transferred from one to the other should be borne in mind.

I wish to thank Mr P. M. Aichroth for permission to report his patients and the Photographic Department of Queen Mary's Hospital. Roehampton, for the illustrations

\section{REFERENCES}

Kirkup JR. Traumatic femoral bone loss. J Bone Joint Surg [Br] 1965: 47. B: $106-10$.

Lynch AF. The broken bone without a fracture: a case report. Injury $1980-1: 12: 2567$.

Ziperman HH, McGinty JB. Traumatic intra-thoracic tibia: case report. J Trauma 1964:4:400 7 .

\section{A NEW TEST FOR CLINICAL UNION OF THE FRACTURED SHAFT OF FEMUR}

\section{N. J. BARTON}

When a patient with a fracture of the shaft of the femur is being treated by traction on a Thomas' splint, it is difficult to test for clinical union by the usual method of applying an angulatory stress and assessing discomfort and movement. To do so one must release the traction and any extra splints which are being used; this may result in loss of position if the fracture is not united, and is moreover rather time-consuming.

However, it is possible to test for clinical union quickly and simply without disturbing the splintage by applying a rotational force. This is done by moving the greater trochanter anteriorly, causing medial rotation of 